\section{DEBATES SOBRE EL ESTRUCTURALISMO Y NEOESTRUCTURALISMO LATINO- AMERICANO: SITUANDO AL ESTADO EN UN PRIMER PLANO DE ANÁLISIS}

DEBATES ON LATIN AMERICAN STRUCTURALISM

AND NEO-STRUCTURALISM: PLACING THE STATE AT THE FOREFRONT OF THE ANALYSIS

VÍCTOR RAMIRO FERNÁNDEZ ·

EMILIA ORMAECHEA ·

Instituto de Humanidades y Ciencias Sociales del Litoral, Universidad Nacional del Litoral / Consejo Nacional de Investigaciones Científicas y Técnicas (IHUCSO-UNL/CONICET) (Argentina).

Email: rfernand@fcjs.unl.edu.ar

Email: eormaechea@fcjs.unl.edu.ar

\section{Resumen}

El artículo constata un vacio en cuanto a los estudios sobre el rol del Estado en la propuesta de desarrollo cepalina y revaloriza las especificidades de los procesos de configuración e implicación estatal para comprender la incapacidad del Estado para direccionar el patrón acumulativo hacia una transformación estructural que incorpore a la industria como motor de desarrollo. En ese sentido, analiza cómo las prácticas estatales desplegadas durante el período de la industrialización por sustitución de importaciones terminaron actuando, por un lado, de manera funcional a la recreación de los obstáculos que daban especificidad al patrón de acumulación periférico, y, por otro lado, configurando la propia debilidad del Estado para afrontar las consecuentes transformaciones del capitalismo luego de 1970.

\section{Registro bibliográfico}

FERNÁNDEZ, VÍCTOR RAMIRO y ORMAECHEA, EMILIA «Debates sobre el estructuralismo y neoestructuralismo latinoamericano: situando al Estado en un primer plano de análisis», en: ESTUDIOS SOCIALES, revista universitaria semestral, año XXX, n 58, Santa Fe, Argentina, Universidad Nacional del Litoral, enero-junio, 2020, pp. 231-254.

\section{Abstract}

The article highlights a gap in the studies on the role of the State in the proposal of ECLAC development and reassesses the specificities of the configuration and involvement practices of Latin American States in order to understand their inability to direct the accumulative pattern towards a structural transformation. In this sense, the practices deployed on and from the States during the period of import substitution industrialization are analysed, showing how they finally acted, on the one hand, in a functional way to the recreation of the obstacles that gave specificity to the pattern of peripheral accumulation, and, on the other hand, configuring the own weakness of the States to confront the consequent transformations of capitalism after 1970.

\section{Descriptores · Describers}

Estado / desarrollo / América Latina / CEPAL State / development / Latin America / ECLAC

Recibido: 27 / 02 / 2018 Aprobado: 16/10/2018 


\section{INTRODUCCIÓN}

La contribución del estructuralismo latinoamericano, elaborada en el marco de la Comisión Económica para América Latina y el Caribe (CEPAL), contribuyó al entendimiento de los problemas para el desarrollo de las economías regionales desde una perspectiva latinoamericana y original (CARDOSO, 1977). El argumento partía de distinguir economías centrales y periféricas, en función de la capacidad de unas y otras para la generación y apropiación de los frutos derivados del progreso técnico. Ante el atraso tecnológico de América Latina, el estructuralismo destacó la imperiosa necesidad de cualificar su estructura productiva y propuso una estrategia de desarrollo basada en la Industrialización por Sustitución de Importaciones (ISI), con énfasis en la intervención estatal.

Aunque inicialmente estas contribuciones les otorgaron un sustento teórico a las experiencias industrializadoras que por entonces ya venían desenvolviéndose en algunos países de la región, lo cierto es que esas experiencias pronto comenzaron a manifestar claras restricciones, tanto para avanzar en los estadios más complejos de la ISI, como para resolver la persistente heterogeneidad estructural, profundizada, paradójicamente, por la misma estrategia desarrollista (PINTO, I965).

El reconocimiento de que las características que asumía la industrialización latinoamericana no eran sinónimo de desarrollo dio lugar a un nuevo contexto de producción teórica en el que desde distintos espacios —ubicados dentro y en la periferia intelectual del estructuralismo- fueron emergiendo diversos aportes para comprender las dificultades experimentadas bajo la IsI y el alejamiento de los resultados obtenidos respecto de las expectativas iniciales. En ese sentido, no obstante las divergencias en las perspectivas analíticas, tanto el estructuralismo tardío $^{1}$ como los enfoques asociados a los debates de la dependencia destacaron que las dinámicas sociopolíticas presentes en América Latina se constituían en un elemento central para explicar la imposibilidad de transformar su estructura productiva. En estos análisis, lejos de actuar como el sujeto transformador del desarrollo latinoamericano, el Estado aparecía o como un actor funcional a las

1] En referencia a la producción de autores articulados a la CEPAL durante 1960 y 1970 que, complejizando el análisis inicialmente economicista, incorporaron al estudio del desarrollo las dimensiones asociadas a los actores y las relaciones de poder en América Latina, y el modo en que operaban bajo las transformaciones sociales que eran consecuencia de la ISI. Ver, por ejemplo, los trabajos de CARDOSO Y FALETTO (1969), GRACIARENA (1972), MEDINA ECHAVARRÍA (1963), PINTO (1973), PREBISCH (1976), QUIJANO (1968), SUNKEL (1967) Y WOLFE (1976), entre otros. 
restricciones del proceso acumulativo (PREBISCH, 1976, 1980), o bien como un actor funcional a la recreación del sistema hegemónico capitalista desigual, excluyente y dependiente (DOS SANTOS, I970; MARINI, I976).

De todas maneras, hacia 1980, estas perspectivas fueron quedando progresivamente marginadas del análisis académico y político, principalmente frente al advenimiento de la ofensiva neoliberal y su renovado discurso en la región. Impulsada por una contraestrategia del capital a escala global, y desde una postura ampliamente crítica a las restricciones experimentadas bajo la ISI, esta ofensiva promovió la desarticulación del entramado industrial y de las políticas que le habían dado estímulo y sustento (basadas, en gran medida, en las contribuciones cepalinas), como también, y no secundariamente, la desactivación del pensamiento crítico latinoamericano.

Aun cuando la década de 1980 se caracterizó por una menor influencia de la CEPAL en los debates académicos y políticos de la región, la misma institución fue generando un proceso de revisión de los postulados del estructuralismo original, con el fin de identificar las restricciones del planteo inicial y adaptar su estrategia a los nuevos desafíos del capitalismo global (віELsCHowsky, I998). Sin embargo, este proceso de revisión, que finalmente dio lugar al paradigma neoestructuralista, terminó desplazando aquella matriz analítica crítica y original, al tiempo que desactivó las discusiones de las décadas posteriores que habían contribuido a enriquecer los debates del subdesarrollo latinoamericano. Concretamente, el nuevo discurso cepalino se focalizó en resaltar las restricciones analíticas asociadas a la teoría económica, argumentando el anterior descuido de dimensiones claves como las financieras, monetarias e inflacionarias, así como la necesidad de promover, centralmente, el estímulo de la productividad y la competitividad (CEPAL, I990).

Lo que interesa destacar, de manera más precisa, es que aquel proceso de revisión neoestructuralista omitió la consideración teórico-analítica de uno de los actores centrales en la propuesta cepalina inicial para el impulso y la coordinación de la IsI: el Estado. Ello no quiere decir que las referencias al Estado hayan estado completamente ausentes, sino que las mismas no se tradujeron en un tratamiento más detenido sobre las características que el mismo desarrolló en sus mecanismos de estructuración e implicación bajo la trunca experiencia industrializadora. En ese sentido, ya siendo deficitaria esa reflexión al interior del propio estructuralismo, el neoestructuralismo persistió — cuando no agravó - en este déficit, restringiendo su capacidad para dar cuenta de los factores que, en relación con los Estados, 
también explican los estrangulamientos del proceso sustitutivo y la perdurabilidad del posicionamiento periférico y dependiente.

La importancia de atender a estas dimensiones asociadas a las formas de organización e implicación del Estado, radica en que las mismas contribuyen a identificar los aspectos estructurales que potencian y condicionan su capacidad de acción, orientada, en este caso, a la ambiciosa tarea de direccionar el proceso de transformación estructural preconizado por el estructuralismo. Analíticamente, la dimensión organizacional del Estado se asocia a la capacidad de configurar estructuras dotadas de cohesividad en sus instancias competenciales y coherencia en sus dispositivos decisionales y logísticos, desde los cuales poder definir e implementar políticas que alcancen los objetivos buscados (CHIBBER, 2002). Esta noción se contrapone con aquellas modalidades de reproducción intraestatal que generan múltiples instancias desarticuladas, solapan competencias y contradicen decisiones, en función de las trayectorias históricas que forman y de las tensiones que se generan con los actores sociales. Al mismo tiempo, esa dimensión organizacional condiciona la otra dimensión asociada a la capacidad implicativa, entendida como la aptitud para desarrollar acciones desde el Estado que condicionen/orienten/direccionen el comportamiento de los actores sociales y administren sus conflictos sin que los mismos se trasladen al interior del Estado y manipulen su configuración.

El argumento presentado en este artículo sugiere que al situar a los Estados latinoamericanos en el centro de análisis, y al considerar las características que asumieron su configuración organizacional e implicativa durante la IsI, es posible comprender por qué los mismos no lograron dirigir la estrategia de industrialización como medio para lograr el desarrollo latinoamericano y resultaron, en cambio, funcionales a la recreación de la forma periférica de acumulación, obstaculizando el cambio estructural teorizado por el estructuralismo. Ello demanda abordar el análisis de las restricciones iniciales del planteo estructuralista desde una perspectiva aun escasamente abordada por la CEPAL, asociada a las particularidades que asumen los Estados latinoamericanos en su configuración e intervención en la periferia, y las dificultades que se presentan, a partir de esas dimensiones, para viabilizar una estrategia de desarrollo.

Para dar cuenta de ello, el trabajo analiza, primero, el rol que asumió el Estado en la teoría estructuralista latinoamericana, y luego, su evolución y complejización analítica bajo el estructuralismo tardío y la(s) teoría(s) de la dependencia. En ese recorrido, se señala la persistencia de diversas restricciones analíticas que se harán 
más explícitas bajo el paradigma neoestructuralista a partir de la desactivación de las dimensiones del conflicto, clases y poder que habían comenzado a emerger con más fuerza en las discusiones de la década de 1960. Seguidamente, con el fin de retomar las contribuciones del estructuralismo y cualificar su propuesta respecto el abordaje estatal, se destaca la centralidad que asumen el tipo de estructuras y las formas implicativas del Estado para explicar tanto los límites de la IsI como las restricciones experimentadas por el Estado para enfrentar la consecuente transformación del capitalismo a escala global. Para ello, y sin desconocer las especificidades nacionales, se analizan las características que presentaron los Estados latinoamericanos en relación con sus estructuras organizativas y sus prácticas de implicación, desde las cuales se explica su incapacidad para actuar transformadoramente sobre la dinámica de acumulación periférica. Es decir, se propone resaltar cómo las características asumidas por el Estado en dicho proceso terminaron ubicándolo como un recreador (y no resolutor) de los elementos definitorios del posicionamiento periférico y dependiente. En este sentido, la estrategia utilizada es dar cuenta de cómo a través del análisis del proceso de formación organizacional e implicativo del Estado ganan comprensión los límites que experimentó el proceso de desarrollo basado en la industrialización y, a partir de ello, los cambios que atravesó el estructuralismo y que dieron lugar al neoestructuralismo. Por último, se presentan las conclusiones del trabajo.

\section{LA CENTRALIDAD DEL ESTADO EN EL ESTRUCTURALISMO LATINOAMERICANO}

La originalidad del estructuralismo no radica solamente en su irrebatible interpretación acerca de las condiciones que relegan a América Latina a un posicionamiento periférico y dependiente, sino también en la incorporación activa del Estado como sujeto transformador de las dinámicas de acumulación de la periferia. En el contexto de su emergencia, bajo la incipiente consolidación de la hegemonía norteamericana (ARRIGHI, 1999) y su creciente permisividad a la intervención estatal en los países centrales, esta interpretación acerca del rol del Estado fue uno de los elementos más cuestionados del estructuralismo por parte de las principales potencias económicas (CARDOSO, 1977). Las razones deben localizarse en un argumento que promovía la intervención estatal a partir de identificar un esquema de reproducción capitalista desigual, cuyos mecanismos de intercambio generaban una dinámica centrípeta, excluyente y subordinante para los países latinoamericanos. 
El rol fundamental del Estado se asociaba a su capacidad para diseñar, impulsar y coordinar la estrategia industrializadora ( que le permitiría a los países periféricos ir captando parte del fruto del progreso técnico, absorber el potencial humano en dicha actividad y contribuir, mediante el incremento de la productividad, al aumento del producto total (CEPAL, I954; PREBISCH, [1949] 1986). En consecuencia, dado que la intervención del Estado se asociaba con ese fin determinado (impulsar y coordinar la ISI), era preciso contar con un programa de desarrollo que ordene las inversiones y los sectores a estimular, para compatibilizar las acciones de los actores privados con los requerimientos del programa.

En ese plano, al Estado se le reconocen diversas herramientas institucionales que le permitirían incidir directa o indirectamente sobre el comportamiento de los actores privados. Principalmente, el Estado puede regular la actividad económica mediante la configuración impositiva, la inversión pública, el control de importaciones, la potencial aplicación de gravámenes sobre el gasto y consumo, o bien, la aplicación de controles de cambios o impuestos a aquellas importaciones que sean incompatibles con el ritmo de crecimiento esperado (PREBISCH, 1952). Además, al Estado se le asigna una responsabilidad fundamental para evitar que los esfuerzos que se implementen logren resultados no deseados (PREBISCH, [I949] I986).

Este planteo marca una clara distancia del pensamiento neoclásico y su concepción sobre la intervención estatal, principalmente porque parte de reconocer que el libre mercado no abona al desarrollo de la periferia, y porque supone que es mediante el rol activo del Estado que las dinámicas de acumulación pueden ser transformadas hacia la construcción de un patrón industrial más inclusivo. $\mathrm{Al}$ mismo tiempo, aun cuando emparenta con el keynesianismo, marca una diferencia respecto el mismo, en tanto en la periferia el rol del Estado no solo está asociado al estímulo de la demanda efectiva o al empleo de los recursos existentes (BUSTELo, I999), sino principalmente a afrontar la transformación del patrón de crecimiento y de las estructuras productivas heterogéneas (PINTO, 1965). En ese sentido, los Estados periféricos tienen un rol mucho más profundo y complejo que los países centrales para la promoción del desarrollo (GURRIERI, 1987).

Durante estos primeros años de producción cepalina prevalece una concepción del Estado que es en gran medida optimista. Se los supone configurados en base a los criterios de neutralidad, racionalidad y eficiencia (CEPAL, 1955); y capaces, por ello, de analizar objetivamente las necesidades del desarrollo (CEPAL, I954) e implementar 
las acciones que le fueron asignadas (FURTAdo, I958; Prebisch, 1952). Predomina, así, una concepción de Estado tecnocrático, capaz de llevar adelante una tarea formidable y ambiciosa para transformar la estructura productiva latinoamericana.

\section{DESDE LAS ACTUALIZACIONES A LAS PERVIVIENTES RESTRICCIONES TEÓRICAS DEL ESTRUCTURALISMO Y SU ABORDAJE ESTATAL}

$\mathrm{Al}$ ir haciéndose evidente que la IsI no era sinónimo de desarrollo, y que la misma presentaba serias restricciones (HIRSCHMAN, I968), comenzaron a gestarse nuevos aportes para comprender las dificultades asociadas a la implementación de dicha estrategia. Inicialmente, esos aportes provinieron de los mismos autores estructuralistas que reconocían que los mecanismos de intervención estatal desplegados no eran los esperados para direccionar la transformación estructural. En ese sentido, las referencias al Estado por parte de autores como Prebisch y Furtado irán demostrando el paso de un optimismo inicial hacia un claro descontento (De almeida, 2OII; ORMaechea y fernández, 20I7). De acuerdo con Prebisch, los Estados, lejos de configurarse en base a los supuestos criterios de eficiencia y racionalidad, intervenían para disminuir las consecuencias socialmente negativas de la insuficiente dinámica industrial, al incorporar en sus estructuras una cantidad de trabajadores mayor a la requerida para el ejercicio de sus funciones porque no lograban ser absorbidos por aquel sector (PREBISCH, 1963). Por su parte, el reconocimiento crítico de Furtado advertía que, producto de las transformaciones socioeconómicas experimentadas durante la ISI, se hacían presentes en el plano político diversos intereses de manera tensionada y no convergente, que condicionaban y limitaban los mecanismos de intervención estatal (FURTADO, 1964, 1965).

Al tiempo que estos trabajos tenían lugar, y a lo largo de 1960, la producción cepalina dará cuenta de una complejización aun mayor de su marco analítico para el estudio de la condición periférica latinoamericana, sobre todo luego de la creación de la División Social de la CEPAL y del Instituto Latinoamericano de Planificación Social y Económica; pero también —y no secundariamente- como consecuencia de la revolución cubana y su influencia teórica y política en la región (PALMA, 1987). Bajo un nuevo contexto de producción, en el que se combinan aportes y preocupaciones que emparentarán —aunque conservando sus notables diferencias - con los debates de la dependencia, fueron emergiendo nuevos tra- 
bajos que señalaban la necesidad de complementar la matriz analítica cepalina predominantemente economicista y de incorporar diversos aportes provenientes de la sociología del poder, el conflicto, las clases sociales y la dominación (CARDOSO Y FALETTO, I969; CEPAL, I963; FURTADO, I966; GRACIARENA, 1976; MEDINA ECHAVARRÍA, I963; PINTO, I965, I973; QUIJANO, I968; SUNKEL, I967, I970).

Particularmente, estos trabajos resaltaban las tensiones sociopolíticas producto de la coexistencia de los actores tradicionalmente dominantes y de aquellos emergentes bajo la IsI, cuyas demandas se posicionaban con mayor fuerza en la escena política. Al revalorizar la dimensión histórica referente a la conformación de los actores dominantes a nivel local, el establecimiento de diferentes alianzas y la consolidación de nuevos actores políticos (CARDOSO Y FALETTO, I969; QUIJANO, I968), los Estados latinoamericanos — y sus modalidades de acción — se posicionaban como un elemento estructural importante para explicar tanto las condiciones de subdesarrollo y dependencia, como las posibilidades de desarrollo de los países.

En sintonía con esta complejización del marco analítico cepalino, la producción teórica de Raúl Prebisch de fines de 1970 y principios de 1980 también dará cuenta de la incorporación de aquellas contribuciones sociopolíticas emergidas bajo este "clima de época». En sus referencias al Estado, adoptará un enfoque que reconocerá en mayor medida - y explícitamente- las relaciones de poder y de clase. Así, al precisar los obstáculos que se oponían al desarrollo latinoamericano, Prebisch señalará que los Estados actuaban legitimando una captura del excedente que limitaba el potencial acumulativo ante la imposibilidad de compatibilizar la transformación de la estructura productiva con los reclamos de mayor redistribución (PREBISCH, I976, I980). Finalmente, cuando las presiones sobre el excedente se volvían insoportables, los Estados intervenían desarticulando la fuerza de trabajo organizada, dejando inalterada la estructura de poder basada en la concentración de la tierra y el patrón de acumulación primario-exportador.

A su vez, esta producción del período tardío-estructuralista entró en tensión con otras perspectivas (también) asociadas al enfoque de la dependencia, pero cuya influencia y antecedentes no eran las iniciales contribuciones cepalinas sino las viejas discusiones inspiradas en las corrientes marxistas (principalmente, en los autores clásicos del imperialismo como Bujarin, Luxemburgo y Lenin). Los teóricos asociados a este enfoque del dependentismo (BARAN, I957; DOS SANTOS, I970; FRANK, I965; MARINI, 1972) no solo señalaban las restricciones de la industrialización como estrategia de desarrollo al cuestionar el rol progresista que el capitalismo podría 
asumir en los países periféricos (KAY, I99I), sino que denunciaban, directamente, la imposibilidad del desarrollo de la periferia dentro del capitalismo, lo que implicaba, en rigor, una crítica directa al optimismo cepalino (MARINI, I994).

En general, más allá de las diferencias analíticas y políticas entre los «estructuralistas tardíos» y los dependentistas, lo cierto es que estos trabajos, que prestaban una mayor atención al Estado y a sus vínculos con la matriz social de poder y conflicto de intereses, se centraron en un entendimiento del mismo en tanto relación de dominación, prestando poca atención al aparato estatal y sus actividades (GURRIERI, I987). En ese sentido, quedaron marginadas, por un lado, la consideración de la forma en que los procesos socioconflictuales coagulaban en determinadas estructuras o aparatos estatales y las formas operativas de los mismos; al tiempo que, por otro lado, quedó desconsiderado el modo en cómo desde esas estructuras y formas operativas se restringían las capacidades del Estado para profundizar la ISI y superar los factores que reproducían la condición periférica.

De todas maneras, lo cierto es que todo el debate que tuvo lugar en América Latina, así como su influencia en términos académicos y políticos, no sobrevivió a la fase de agotamiento de la isI. En ello intervinieron diversos factores que se hicieron presentes en un escenario cada vez más complejo. Por un lado, luego de la crisis de 1973, el capitalismo atravesaba un proceso de reconfiguración de sus dinámicas de acumulación y reproducción a escala mundial (HARVEY, 1998; JESSOP, 2008). Dicha reconfiguración, impulsada tanto por las fracciones productivas y financieras del capital global, como por el complejo regulatorio que amalgamaba el papel dominante de Estados Unidos en el sistema interestatal (PEET, 2009), estuvo acompañada por la promoción de un renovado discurso de desarrollo, que reposicionó en la escena política y académica a la teoría neoclásica, con el consecuente ataque a las características que asumieron los Estados de Bienestar en los países centrales y los Estados interventores de la periferia (TOYE, 1987). En relación con América Latina, esa nueva ofensiva conllevaba una agresiva acción desregulatoria y privatizadora, con numerosas políticas de desindustrialización y desimplicación selectiva del Estado (FERNÁNDEZ, TEALDO y VILLALBA, 2005), facilitadas por la recomposición del tradicional bloque dominante (representado por los actores más concentrados y extranjerizados) y por las diversas olas de interrupciones democráticas que se sucedieron en la región.

Por otro lado, a ese complejo escenario se sumaban las dificultades del estructuralismo para proponer una alternativa al enfoque neoclásico y a su exitosa 
pretensión de instalar un renovado imaginario global de autorregulación. Estos elementos, sumados a las crecientes críticas que se volcaban sobre los resultados de la ISI y la intervención estatal, así como directamente sobre la política de desarrollo de la CEPAL, dificultaban la propuesta de contar con un Estado capaz de direccionar las transformaciones requeridas en el patrón de acumulación periférico. De esta manera, y luego de haber quedado estigmatizada como promotora del intervencionismo (SZTULWARK, 2005), la CEPAL inició un período de posicionamiento defensivo y de menor influencia en los asuntos políticos y académicos latinoamericanos (BIELSCHOWsKY, 1998).

La combinación de aquellos factores impulsó a la CEPAL a iniciar durante I980 un proceso de revisión acerca de las contribuciones y restricciones analíticas contenidas en su planteo original, no solo para comprender las limitaciones experimentadas bajo la ISI, sino también para adaptar dichas estrategias al nuevo escenario global. Alejándose de los enfoques desarrollados durante los sesenta y setenta, que resaltaban la dinámica sociopolítica y conflictual del capitalismo en la periferia, gran parte de los análisis elaborados por los autores articulados en la institución se orientaron a destacar las debilidades analíticas del estructuralismo relacionadas con la desatención de las dimensiones económicas.

De acuerdo con estos argumentos, el estructuralismo se caracterizó por una limitada preocupación por el manejo de las variables macroeconómicas, la escasa atención de los aspectos monetarios, financieros e inflacionarios, el pesimismo exagerado frente a los mercados externos, la sobrevalorización del proteccionismo económico, y la escasa reflexión sobre las políticas de mediano plazo que vincularan los objetivos nacionales del desarrollo con la planificación (BITAR, I988; FFRENCH-DAVIS, I988; ROSALES, I988; SUNKEL Y ZULETA, I990). Al mismo tiempo, y no obstante la centralidad de estas dimensiones en los escritos iniciales de la CEPAL, desde neoestructuralismo revalorizó la necesidad de incrementar auténticamente la productividad y competitividad, influenciados por el proceso que tuvo lugar en el este asiático (CEPAL, I990; FAJNZYLBER, I990), y de resolver los persistentes problemas del desequilibrio en las balanzas de pagos (FISHLOw, 1987).

El predominio de las interpretaciones economicistas no se tradujo, de todas maneras, en una ausencia de reflexiones sobre el Estado; más bien, el Estado aparece como uno de los ejes principales de revisión. Pero la perspectiva desde la cual se lo interpela está asociada a la necesidad de garantizar la eficiencia de su intervención (ROSALES, 1988). Gran parte de la crítica teórica y empírica referente 
a la estrategia industrializadora se centró en señalar diversos excesos, tales como la burocratización, la ineficiencia, la inadecuada asignación de recursos (CEPAL, 1990) y la sobrevaloración del proteccionismo estatal, que en la práctica adquirió un carácter frívolo (FAJNZYLber, 1983) y desvirtuó el funcionamiento de las economías. También se advirtió sobre la poca consideración analítica otorgada a los instrumentos de política económica para lograr los objetivos buscados (BITAR, I988; FISHLOW, I987; ROSALES, I988).

Más allá de estas referencias críticas, el neoestructuralismo no desestima la intervención estatal, sino que la incorpora estratégicamente para la promoción del cambio estructural. Bajo un proceso de redefiniciones teóricas y políticas, la concepción de Estado predominante pasará a ser la de un Estado subsidiario (CEPAL, I990; Faletto, 1996). A partir de la influencia de los trabajos de Fajnzylber, al Estado se le asignarán las dos tareas cruciales de superar las carencias acumuladas en los ámbitos de la equidad y la competitividad internacional, sobre un patrón de intervención que debe someterse a una amplia «concertación estratégica» entre las distintas fuerzas representativas (FAJNZYLBER, I990; CEPAL, I990). Es decir que, no obstante las ambiciosas tareas que se le asignan al Estado, el discurso que predomina es el de un Estado del cual no se requiere una intervención amplia o extensa (BITAR, 1988), sino que sea autolimitada y simplificada, y que se desenvuelva en una dinámica de sinergias y colaboración con los actores privados.

En suma, el análisis de revisión neoestructuralista no solo desplazó la consideración de la matriz sociopolítica del poder, conflicto y dominación que había comenzado a complementar el debate durante los sesenta y setenta, sino que omitió definitivamente el examen de aquellos factores que, en relación con las particularidades de los Estados, restringieron su capacidad para actuar sobre los factores que configuran la condición periférica.

No resulta irrelevante, por lo tanto, destacar que los límites analíticos del estructuralismo, particularmente de aquellos asociados al análisis Estado, se enmarcan dentro de una progresiva evolución asociada al reconocimiento del papel del poder, el conflicto y la dominación, y cómo se involucra, a partir de esas categorías, el Estado. No obstante, dicha evolución dejó pendiente aquellos aspectos vinculados al modo en que las estructuras y capacidades del Estado son afectadas por las distintas lógicas a partir de las cuales opera ese poder y las tensiones ligadas al mantenimiento o disputa de esa dominación, limitando su capacidad para direccionar el proceso de transformación estructural. El giro ensayado por el 
neoestructuralismo, en cambio, marcó una involución, justamente al desactivar esas categorías y al posicionar al Estado en un lugar vulnerable, que no desconocía su presencia pero facilitaba su enjuiciamiento histórico, sin reconocer los procesos que afectaron su configuración y capacidad de direccionamiento en un contexto de profundas transformaciones del capitalismo y del rol de la(s) periferia(s).

La recuperación cualificada de las contribuciones del estructuralismo tardío y algunas variantes de los enfoques de la dependencia se impone, por lo tanto, como una agenda de análisis superadora de las limitaciones del enfoque neoestructuralista. Al mismo tiempo, se presenta como un camino necesario para comprender las limitaciones enfrentadas durante periodo de IsI y, luego, ante las transformaciones posteriores a la crisis capitalista de 1970. A nivel de las ideas y las propuestas, se impone también para dar cuenta de las restricciones que operaron al interior de la propia CEPAL para enfrentar explicativa y propositivamente esos aspectos, que alentaron, en cambio, una lectura no conflictualista sobre los modos de acoplamiento de la periferia a los más recientes procesos de globalización (FERNÁNDEZ, 2OI7).

La dimensión cualificadora de esa recuperación se asocia, precisamente, a la necesidad de dar cuenta de cómo los procesos socioconflictuales terminaron coagulando en determinadas estructuras o aparatos estatales (GURRIERI, I987), condicionando el modo asumido por la implicación del Estado y su consecuente incapacidad para alterar las estructuras productivas heterogéneas y primarizadas.

\section{LA DEBILIDAD DEL ESTADO LATINOAMERICANO PARA EL DIRECCIONAMIENTO DE LA ESTRATEGIA DE DESARROLLO}

Al ubicar al Estado en un escenario conflictual, mediado por lógicas de poder que incluyen las tensiones por la dominación y la amenaza de desplazamiento de los dominantes, y al entender la incidencia de estos aspectos en su configuración organizacional e implicativa, es posible comprender, desde otra perspectiva, las limitaciones relacionadas con su incapacidad para transformar la estructura productiva sobre la base de una cualificación industrial y evitar reincidir en un patrón de inserción subordinada durante las transformaciones posteriores a la crisis de 1970. En otras palabras, el Estado que emergió como consecuencia de las transformaciones en el plano socioeconómico y político, específicamente luego de la Segunda Guerra Mundial (FERnÁndez y ormaEcheA, 2OI8), quedó inserto en 
una dinámica conflictual que no habilitó la construcción de una institucionalidad adecuada para superar la heterogeneidad estructural y el patrón de inserción internacional primarizado.

En la explicación de este proceso intervienen diversos factores, tales como las características que asumió la matriz social de actores en estos países, y el modo en cómo los conflictos expresados en dicha matriz actuaron sobre - y se retroalimentaron en- el Estado. Ello contribuye a explicar las limitaciones del Estado para resolver las tensiones que se agudizaban en el plano de la acumulación y los conflictos derivados de las exigencias crecientes de una mayor redistribución.

En general, y siempre salvando las especificidades históricas de las diferentes trayectorias nacionales (CARDOSO Y FALETTO, 1977), las lógicas reproductivas de los actores presentes en América Latina se desarrollaron bajo un escenario conflictual en el que se fueron consolidando comportamientos poco propensos a cubrir los requerimientos que demandaba la superación de la etapa fácil de la IsI. En ese sentido, a diferencia del proceso que tuvo lugar en el este asiático, las estrategias sustitutivas derivadas de las condiciones impuestas por la autarquía relativa no corrieron paralelo a una reforma estructural en el régimen de tenencia de la tierra y fueron, por lo tanto, funcionales a la preservación de la estructura de poder de las oligarquías nativas (KAY, 2002). Estas lograron preservar sus comportamientos rentistas y escasamente innovadores, y su rol de clase exportadora proveedora de las principales fuentes de divisas en la región (o'DONNELL, I972).

Al mismo tiempo, la pervivencia de estos actores dominantes fue contextual a la activación vertical, desde el Estado, de un conjunto de actores, representantes del pequeño capital productivo y comercial, y del ampliado mundo del trabajo, resultado del proceso de industrialización y urbanización de entreguerras (GRACIARENA, 1990). En ese marco, las crecientes demandas de estos activados (o'DONNELL, 1972) pasó a ser atendida por el Estado a partir de la ampliación del régimen político, en la que no estuvieron ausentes diversas formas de clientelismo (GRACIARENA, I984).

Sin embargo, el mayor reconocimiento a las demandas de los nuevos actores políticos convivió, al mismo tiempo, con otros dos procesos asociados que fueron limitando la posibilidad de avanzar en una transformación estructural. El primero está asociado a la incapacidad de resolver la continuidad del proceso de acumulación a través de la ISI y avanzar en la etapa difícil (PINTO, I980); y, el segundo, a la incapacidad del Estado, aun en su creciente protagonismo, de enfrentar esas limitaciones en el plano de la acumulación y destrabar las tensiones derivadas de ello. 
En relación con el primero de esos procesos, las dificultades para avanzar en los estadios más complejos de la IsI se hacían evidentes frente a los requerimientos no convergentes entre los actores tradicionalmente dominantes, asociados al viejo modelo agroexportador y el capital externo (ROMERO Y ROFMAN, 1974), y la atención, por parte del Estado, de los actores activados, que pugnaban por una distribución sostenida del ingreso. A su vez, toda esta tensión tenía lugar bajo la ausencia de una burguesía que asuma como propio el proyecto de desarrollo industrial (CARDOso, I964; FALETTO, 1996), y que esté dotada de capacidad de aprendizaje intensivo y propensión a desarrollar las formas no rentistas que demandaba el éxito de la ISI (HIRSCHMAN, 1968). Justamente, la ausencia de este actor en medio de ese proceso de tensiones fue posicionando al Estado como epicentro de soluciones transitorias que lo hacían incapaz de operar como un resolutor de los problemas estructurales de las economías latinoamericanas.

La preservación del poder concentrado de los actores tradicionales al interior del bloque que direccionaba el proceso de acumulación actuó fortaleciendo su poder de acción sobre el Estado, restringiendo sus modalidades de implicación y alejando a esta de cualquier reorientación de sus comportamientos acumulativos. Es decir que este bloque dominante no fue ajeno a las limitaciones del Estado para desarrollar una implicación capaz de redefinir los comportamientos de los actores capitalistas dominantes, para orientarlos —y condicionarlos_ a desarrollar un proceso acumulativo más complejo, que dé sostenibilidad a las acciones redistributivas y permita atender los reclamos de los actores activados.

La imposibilidad de operar sobre aquel direccionamiento conllevó una restricción intrínseca para superar la etapa fácil de la ISI. Como consecuencia, a medida que dicha fase se agotaba, y no obstante la importancia que la actividad industrial adquiría en la mayoría de los aparatos económicos, se potenciaba la vulnerabilidad asociada a los desbalances en las cuentas externas y se reforzaban las formas de inserción dependientes (FFRENCH-DAVIS, MUÑOZ, Y PALMA, 1998), al tiempo que, internamente, se mantenía y profundizaba la heterogeneidad estructural (PINTO, I973).

La apelación al capital externo - en particular, a la inversión extranjera a través de la empresa trasnacional — fue ganando peso en las argumentaciones que exploraban las salidas para América Latina, sin excluir en ello a los propios intelectuales estructural-dependentistas, propulsores de un desarrollo dependiente asociado (CARDOSO Y FALETTO, 1977). Sin embargo, la empresa trasnacional que arribó en la región, particularmente la estadounidense (KERNER, 2003), tendió a desarrollar 
una lógica acumulativa sustentada en enclaves, importando paquetes tecnológicos en un mercado hiperprotegido y procesos productivos con alta integración vertical en los que escaseaban los encadenamientos productivos intranacionales, lo que potenciaba la transnacionalización del proceso de acumulación (SUNKeL, I97I). Como resultado, la estructura que se fue configurando promovió un patrón de decisiones exógeno, desigualador y poco dinámico.

El segundo de los procesos refiere al progresivo desmoronamiento de la capacidad del Estado para legitimar las tensiones entre el bloque de poder y el grueso cuerpo social activado por la IsI. Las diversas formas distributivas con las que los activados eran atendidos chocaban, en su sostenibilidad, con el mantenimiento de una estructura productiva sustentada en la continuidad de los intereses del bloque de poder y con las consecuencias de una industrialización trunca (FAJNZYLBER, 1983) que no lograba resolver los problemas de desigualación interna y vulnerabilidad externa.

En general, las modalidades de implicación estatal mediante las cuales se resolvían estas tensiones oscilaban entre formas autoritarias, que desactivaban temporariamente a los actores activados (o'DONNELL, 1972), y/o prácticas que combinaban la reducción/desmantelamiento de subsidios y beneficios, y estrategias devaluatorias (DORNBUSCH Y EDWARDS, I99I) que degradaban el salario y fortalecían el posicionamiento de los actores dominantes del capital. En última instancia, estas intervenciones dejaban inalterada tanto la estructura de poder característica de América Latina, como la estructura de reproducción interna (heterogénea y desigualadora) y de inserción internacional (primarizada).

Ahora bien, ¿̨cómo esa dinámica que entrelazó la matriz social dominante con la forma de implicación del Estado periférico latinoamericano operó conformando las estructuras estatales? ¿Qué características tenían estos aparatos como resultado? ¿Qué implicancias tuvo ello sobre la imposibilidad de que el Estado pueda direccionar del proceso de acumulación, tal como lo plantearon los estructuralistas?

Efectivamente, no obstante su protagonismo, el Estado que se fue configurando fue — siempre con un lenguaje polémico — un Estado capturado (HELLMAN Y KAUFMANN, 200I), «direccionado por» y no «direccionante de» los actores dominantes de aquella matriz. Al responder a las demandas de los actores más organizados de la sociedad, fue conformando una estructura de organizaciones múltiples y contradictorias, en respuesta a los distintos intereses, que densificaban su presencia pero que, al mismo tiempo, iban minando su capacidad de coordinación 
estratégica. Ello fue arrojando como resultado un Estado organizacionalmente amplificado en sus estructuras y funciones, pero sin capacidad implicativa para direccionar a los actores que conducían el patrón acumulativo e imponerse sobre el complejo fragmentario de demandas sociales. Producto de esa configuración copada e inconexa, el Estado terminó conminado a implicarse internalizando a través de su estructura y acciones las tensiones derivadas de la lógica mutuamente insostenible de los actores tradicionales y los activados.

De esta manera, la configuración de las estructuras estatales quedó inserta en un proceso no ajeno al conflicto y el poder, en el que acumuladores y beneficiarios de los procesos distributivos, buscando respectivamente preservar posiciones e incorporar acciones, fueron minando las estructuras, abonando progresivamente a una feudalización del Estado por las corporaciones (PORTANTIERO, 1989). En forma inversa a la fortaleza proveniente de la capacidad de penetración y el control del Estado hacia la sociedad civil, a través de redes de actuación (MANN, 2006), el Estado latinoamericano experimentó un engordamiento inconexo de sus estructuras, resultante de la penetración corporativa de actores e intereses divergentes. Fue en este contexto, a mediados de 1960, en que tuvo lugar el nacimiento y desarrollo de los anillos burocráticos (CARDOSO, 1975), en referencia a los vínculos entre el Estado y los grupos de intereses más concentrados de la sociedad, mediante los cuales el primero atendía clientelarmente los requerimientos patrimonialistas de aquellos, por medio de sus managers y de un laberinto de conductos organizacionales (CASTELlani, 2002). En definitiva, estos actores más concentrados profundizaban la captura de rentas al interior del Estado y alentaban el desmantelamiento de su papel distribucionista, al tiempo que depositaban en el capital externo la esperanza — nunca materializada — de la modernización del desarrollo.

Producto de lo señalado, el decurso de la realidad fue mostrando una trayectoria en la que, paradojalmente, a medida que se iba potenciando la necesidad de contar con un Estado capaz de afrontar mayores desafíos que en el centro (GURRIERI, I987), se diluía la posibilidad de conformar en los mismos una estructura idónea y bien articulada para conducir el cambio de comportamientos de los actores dominantes. La imposibilidad de dotarse de una estructura organizacional y operativamente coherente afectaba claramente la capacidad de actuar sobre el proceso acumulativo, sin poder traccionar el comportamiento de los capitalistas vernáculos y externos hacia un patrón de acumulación endógeno y dinámico (AMSDEN, I989; DAVIS, 2004). 
La imposibilidad de resolver a nivel del proceso de acumulación las tensiones de los intereses divergentes entre las dinámicas distributivas cupulares con la preservación de una estructura de poder basada en un capitalismo extrovertido y rentista, terminó forzando una internalización caótica de esas tensiones en el Estado. Ello no solo contribuyó a darle un sello de especificidad negativa a su condición periférica, sino que finalizó diluyéndole como herramienta estratégica para alterar ese patrón acumulativo y revertir el posicionamiento periférico-dependiente. Ante tal fragmentaria y descoordinada reproducción de su infraestructura organizacional, el Estado nunca logró centralizar y poner bajo su control direccionante al capital financiero (FIORI, I992), el que, como es sabido, conformó el elemento de apalancamiento central en las experiencias excepcionales del este asiático (FERNÁNDEZ, 2017), obligándolo a financiarse a través de mecanismos inflacionarios.

Finalmente, el despliegue de las formas autoritarias para laudar el conflicto en favor de los actores más concentrados y exógenos de esa matriz, y resolver temporariamente esas distorsiones, no hizo sino fortalecer su condición periférica a la vez que cristalizar su debilidad estructural para enfrentar las transformaciones del propio patrón acumulativo global. Estas transformaciones, impulsadas desde el capitalismo central ante el agotamiento de las formas hegemónicas de producción y realización fordistas-keynesianas, arribaron firmemente en la región con posterioridad a 1970 y lograron constituirse como un nuevo proyecto político, imponiendo un renovado imaginario del desarrollo sobre la base de la autorregulación del mercado y el desplazamiento de aquella otrora indiscutida centralidad estatal.

\section{CONCLUSIONES}

Partiendo de reconocer el escaso abordaje de las restricciones asociadas al rol direccionador del Estado en el marco de la propuesta de desarrollo cepalina, un objetivo central del artículo fue revalorizar las especificidades de los procesos de configuración e implicación estatal en la comprensión de las incapacidades para direccionar el patrón acumulativo hacia una transformación estructural. En ese sentido, destacamos cómo las prácticas desplegadas sobre y desde los mismos Estados terminaron actuando, por un lado, de manera funcional a la recreación de los obstáculos que daban especificidad al patrón de acumulación periférico, y, por otro lado, configurando la propia debilidad del Estado para afrontar las 
transformaciones del capitalismo a escala global suscitadas con posterioridad a la década de 1970. Esto refiere principalmente a la no alteración y reproducción de una estructura productiva primarizada y heterogénea, y a la recreación, hasta nuestros días, de un posicionamiento subordinado y dependiente.

Aun cuando el abordaje del Estado fue registrando una progresiva evolución y complejización dentro del estructuralismo, este no desarrolló un análisis sobre el modo en cómo los Estados, a través de sus formas estructurales e implicativas, terminaron configurando su propia debilidad direccionadora para actuar sobre el patrón acumulativo. Finalmente, el paso del estructuralismo al neoestructuralismo implicó una clara involución, en tanto no solo no dio respuestas a este interrogante analítico, sino que definitivamente terminó desplazando la centralidad del Estado para el desarrollo latinoamericano, así como las dimensiones de análisis asociadas al poder, conflicto y dominación que también se constituyen en variables explicativas, como procuramos demostrar, de las restricciones asociadas a la estrategia industrializadora y a la perdurabilidad del posicionamiento periférico y dependiente. En consecuencia, retomamos las contribuciones del estructuralismo a los fines de cualificar su propuesta respecto el abordaje estatal, destacando la centralidad que asumen el tipo de estructuras y las formas implicativas del Estado para explicar dichos procesos.

Efectivamente, los procesos conflictuales que tuvieron lugar en América Latina se fueron agudizando luego de la Segunda Guerra Mundial, a partir de la activación de una amplia panoplia de actores que lograron posicionar con mayor fuerza sus reclamos económicos y políticos, pero en un escenario donde el poder de los actores tradicionalmente dominantes permaneció concentrado e inalterado. Ante la imposibilidad de resolver dichos reclamos mediante mecanismos redistributivos sustentados en el despliegue de una estrategia industrializadora que permitiera superar la etapa fácil de Isı, el Estado se vio obligado a implicarse mediante diversos mecanismos que finalmente fueron menguando su capacidad para direccionar el mismo proceso industrializador. Es decir que, sobre la base de un escenario de demandas y conflictos crecientes, el Estado procuró responder a los requerimientos no convergentes que emanaban de los actores tradicionales dominantes y de los activados, conformando, para ello, una estructura de organizaciones múltiples y descoordinadas, que densificaban su presencia sin contar precisamente con modalidades de intervención coherentes para el fin industrializador.

En función de aquellas particularidades que asumieron las prácticas de intervención, el Estado fue configurando su creciente incapacidad para actuar trans- 
formadoramente sobre el patrón de acumulación latinoamericano. Su captura por la dinámica de la multicooptación de rentas y la satisfacción fragmentaria de las demandas vinculadas a los actores sociales realimentó la formación de una infinidad de instancias burocráticas escasamente conexas, pobladas por lobistas, tecnoburócratas y actores políticos que le quitaban capacidad tanto para disciplinar a los actores vinculados a una matriz rentista, como para articular los intereses del complejo y heterogéneo campo de sectores subalternos, necesario para obtener la imprescindible consensualidad y base coalicional de apoyo a sus acciones disciplinarias sobre el capital.

La internalización de los reclamos y las tensiones dentro del Estado fue limitando la posibilidad de conformar una estructura idónea y bien articulada para lograr un cambio en las dinámicas de acumulación periféricas. Lejos de poder direccionar el comportamiento de los actores dominantes hacia la formación de un núcleo productivo industrial, endógeno y dinámico, compatible con los requerimientos de la propuesta estructuralista, esa configuración estatal se realimentó de diversas prácticas redistributivas de corto plazo, sustentadas en la obtención de beneficios selectivos, provenientes de ese proceso de colonización expresado en la multiplicación de estructuras, competencias y recursos de las diferentes agencias estatales (o'DONNELL, 1993). Estas últimas, pasando a formar parte de un progresivo path dependence, contribuyeron a la restricción de la misma maquinaria estatal para fijar objetivos estratégicos y direccionar los comportamientos de actores dominantes y subalternos, en una forma en que la acumulación y distribución alcancen formas de sostenibilidad más razonables y duraderas.

Las limitaciones para superar esas restricciones, agravadas con el ingreso del capital externo y los sucesivos ensayos autoritarios a nivel del Estado, no solo resultan relevantes para observar la incapacidad de colocar a la región como un escenario de superación de la condición periférica mediante la ISI, sino que dejaron ambos frentes altamente vulnerables cuando la crisis cíclica del capitalismo tomó lugar a escala global desde finales de 1960, acompañada de una profunda reestructuración que redefinió los vínculos con la periferia. En tal contexto, la apacible rearquitectura cooperativista del Estado con el mercado como alternativa a la ofensiva neoliberal auspiciada por el neoestructuralismo contrastó con el disciplinante y subordinado acoplamiento del mismo Estado a los objetivos del capital global y sus lógicas de financiarización. La redefinición de las estructuras y formas implicativas no tomó, entonces, un sentido adecuado para modificar 
su patrón acumulativo e insertarlo en el escenario internacional bajo formas que reviertan o atenúen su subalternidad sino, por el contrario, el de integrante de una compleja trama institucional donde la centralización y la fragmentación fueron rediseñadas desde redes económicas y políticas globales que buscaban fortalecer la dominación del centro. La acción de este —y de esas redes—, habilitó una penetración combinada de acciones e ideas que recrearon la colonización del aparato estatal bajo estrategias de resubordinación a las lógicas del capitalismo central que no fueron revertidas, aún bajo las acciones redistributivas que se reiniciaron a inicios del presente siglo. En este escenario, la debilidad estatal heredada facilitó la docilidad en la aceptación del complejo entramado de intereses, estrategias y dispositivos habilitantes de éstos, que recapturaron el Estado para redireccionar su intervención en función de aquellas lógicas resubordinantes.

El peso de la combinación de ideas y poder de los actores que controlan las redes del centro, como bien indicaba Prebisch, deben ser tenidos en cuenta para revalorizar la relevancia de repensar situadamente, desde la periferia, en una forma que recupere las intersecciones de los procesos internos y externos. Ello incluye la reconstrucción precisa de los Estados que fueron construidos, afectando la capacidad de fortalecer los procesos de desarrollo sustentados en la industrialización, y de los Estados necesarios a partir de las transformaciones globales más recientes. La revinculación de los impedimentos históricos en la formación de estructuras y lógicas implicativas de esos Estados para la formación de una dinámica endógena, que abone al desarrollo de la periferia, demanda la reinstalación de la dimensión del poder y la dominación que se desenvuelven a partir de procesos conflictuales, en los que se entrelazan actores, intereses y lógicas internas y externas. El encaminamiento del examen del Estado, su conformación estructural y sus formas implicativas bajo este cuadro resulta entonces un ejercicio epistémico esencial para dar continuidad a la inconclusa trayectoria de análisis estructuralista y superar el nada inocuo desvío neoestructuralista. 


\section{Referencias bibliográficas}

AMSDEN, ALICE (1989): Asia's Next Giant: South Korea and Late Industrialization, New York \& Oxford, Oxford University Press.

ARRIGHI, GIOVANNI (1999): El largo sig/o XX, Madrid, AKAL.

BARAN, PAUL (1957): La economía política del crecimiento, México, Fondo de Cultura Económica. BIELSCHOWSKY, RICARDO (1998): «Cincuenta años de pensamiento de la CEPAL», Revista de La CEPAL, Número Extraordinario.

BITAR, SERGIO (1988): «Neoliberalismo versus neoestructuralismo en América Latina», Revista de La CEPAL n 34, pp. 45-64.

BUSTELO, PABLO (1999): Teorías contemporáneas del desarrollo económico, Madrid, Editorial Síntesis. CARDOSO, FERNANDO (1964): Empresário Industrial e Desenvolvimento Econômico no Brasil, Difusão Européia do Livro.

CARDOSO, FERNANDO (1975): «La cuestión del Estado en Brasil», Revista Mexicana de Sociología, vol. 37, n 3, pp. 603-630.

CARDOSO, FERNANDO (1977): «La originalidad de la copia: la CEPAL y la idea de desarrollo», Revista de La CEPAL, segundo semestre, pp. 7-39.

CARDOSO, FERNANDO Y FALETTO, ENZO (1969): Dependencia y desarrollo en América Latina. Ensayo de interpretación sociológica, Buenos Aires, Siglo XXI. CARDOSO, FERNANDO Y FALETTO, ENZO (1977): «Post scriptum a Dependencia y Desarrollo en América Latina», Desarrollo Económico, vol. 17, n 66 , pp. 273-299.

CASTELLANI, ANA (2002): «La gestión estatal durante los regímenes políticos burocrático-autoritarios. El caso argentino entre 1967 y 1969», Sociohistórica, nº 11-12, pp. 35-68.
CEPAL (1954): La cooperación internacional en la política de desarrollo latinoamericano, Nueva York, Naciones Unidas.

CEPAL (1955): Análisis y proyecciones del desarroIlo económico. México: Naciones Unidas.

CEPAL (1990): Transformacion Productiva con Equidad. La tarea prioritaria del desarrollo de América Latina y el Caribe en los años noventa, Santiago de Chile, Naciones Unidas.

CHIBBER, VIVEK (2002): «Bureaucratic Rationality and the Developmental State», American Journal of Sociology, vol. 107, n 4. pp. 981-959.

DAVIS, DIANE (2004): Discipline and development. Middle Classes and Prosperity in East Asia and Latin America, Cambridge, Cambridge University Press.

DE ALMEIDA, JOÃO (2011): «Encantos e desencantos de Celso Furtado com a racionalidade do planejamento estatal», Cadernos Do Desenvolvimento, vol. $6, n^{\circ} 8$.

DORNBUSCH, RUDIGER Y EDWARDS, SEBASTIÁN (1991):

The macroeconomics of Populism, University of Chicago Press.

DOS SANTOS, THEOTÔNIO (1970): «Dependencia económica y alternativas de cambio en América Latina», Revista Mexicana de Sociología, vol. 32, $\mathrm{n}^{\circ} 2$, pp. 417-463.

FAJNZYLBER, FERNANDO (1983): La industrialización trunca de América Latina, México, Editorial Nueva Imagen.

FAJNZYLBER, FERNANDO (1990): Industrialización en América Latina: de la "caja negra» al casillero vacío, Comparación de patrones contemporáneos de industrialización, Santiago de Chile, CEPAL, Naciones Unidas. 
FALETTO, ENZO (1996): «La CEPAL y la sociología del desarrollo», Revista de La CEPAL, no 58, pp. 191-204.

FERNÁNDEZ, VÍCTOR (2017): La trilogía del erizo-zorro. Redes globales, trayectorias nacionales y dinámicas regionales desde la periferia, Barcelona: Anthropos - Siglo XXI Editores - Ediciones UNL. FERNÁNDEZ, VÍCTOR Y ORMAECHEA, EMILIA (2018): «Prebisch, el Estado y la debilidad del imprescindible», Problemas del Desarrollo. Revista Latinoamericana de Economía, vol. 145, n 49, pp. 77-99.

FERNÁNDEZ, VÍCTOR, TEALDO, JULIO Y VILLALBA, MARTA (2005): Industria, Estado y territorio en la Argentina de los '90. Evaluando la desimplicación estatal selectiva y repensando los caminos del desarrollo, Santa Fe, Ediciones UNL.

FFRENCH-DAVIS, RICARDO (1988): «Esbozo de un planteamiento neoestructuralista», Revista CEPAL, $\mathrm{n}^{\circ} 34$, pp. 9 7-44.

FFRENCH-DAVIS, RICARDO, MUÑOZ, OSCAR Y PALMA, GABRIEL (1998): «The Latin American economies (1950-1990)», en Bethell, Leslie (Ed.), Latin America. Economy and Society since 1930, Cambridge, Cambridge University Press.

FIORI, JOSÉ LUIS (1992): «Economía política del Estado desarrollista en Brasil», Revista de la CEPAL, no 47, pp. 197-201

FISHLOW, ALBERT (1987): «El estado de la ciencia económica en América Latina», Investigación Económica, no 181, pp. 293-330.

FRANK, ANDRÉ GUNDER (1965): Capitalismo y subdesarrollo en América Latina, Siglo XXI.

FURTADO, CELSO (1958): «Fundamentos da programação econômica», Econômica Brasileira, vol. $4, \mathrm{n}^{\circ} 1$ y 2.

FURTADO, CELSO (1964): Dialética do desenvolvimento, Rio de Janeiro, Fondo de Cultura.

FURTADO, CELSO (1965): «Obstáculos Políticos Para el Desarrollo Económico del Brasil», Desarrollo Económico, vol. 4, nº 16 pp. 373-389.

FURTADO, CELSO (1966): «Desarrollo y estancamiento en América Latina (Enfoque estructuralista)», Desarrollo Económico, vol 6, n 22/23, pp. 191-225.

GRACIARENA, JORGE (1972): Poder y clases sociales en el desarrollo de América Latina. Buenos Aires: Paidós.

GRACIARENA, JORGE (1976): «Poder y estilos de desarrollo. Una perspectiva heterodoxa», Revista de La CEPAL, Primer semestre, pp. 173-194 GRACIARENA, JORGE (1984): «El Estado latinoamericano en perspectiva. Figuras, crisis, prospectivas», Pensamiento Iberoamericano, $\mathrm{n}^{\circ}$ 5, pp. 39-74. GRACIARENA, JORGE (1990): "Estado periférico y economía capitalista: transiciones y crisis», en González Casanova, Pablo (Ed.), El Estado en América Latina. Teoría y práctica, Siglo XXI Universidad de las Naciones Unidas.

GURRIERI, ADOLF0 (1987): «Vigencia del Estado planificador en la crisis actual», Revista de La CEPAL, n 31, pp. 201-218.

HARVEY, DAVID (1998): La condición de la posmodernidad. Investigación sobre los orígenes del cambio cultural, Buenos Aires, Amorrortu Editores. HELLMAN, JOEL Y KAUFMANN, DANIEL (2001): «La captura del Estado en las economías en transición», Finanzas y Desarrollo, pp. 31-35.

HIRSCHMAN, ALBERT (1968): «La economía política de la industrialización a través de la sustitución de importaciones en América Latina», El Trimestre Económico, vol. 35, n 140, pp. 625-658.

JESSOP, BOB (2008): El futuro del Estado capitalista, Madrid, Los libros de la catarata.

KAY, CRISTOBAL (1991): «Teorías latinoamericanas del desarrollo», Nueva Sociedad, $n^{\circ} 113, \mathrm{pp}$. 101-113.

KAY, CRISTOBAL (2002): «Reforma agraria, indus- 
trialización y desarrollo ¿Por qué Asia Oriental superó a América Latina?», Debate Agrario, $\mathrm{n}^{\circ}$ 34, pp. 45-94.

KERNER, DAVID (2003): «La CEPAL, las empresas transnacionales y la búsqueda de una estrategia de desarrollo latinoamericana», Revista de La CEPAL, no 79, pp. 85-99.

MANN, MICHAEL (2006): «El poder autónomo del Estado: sus orígenes, mecanismos y resultados», Revista Académica de Relaciones Internacionales, n 5, pp. 1-43.

MARINI, RUY MAURO (1972): Dialéctica de la dependencia, Santiago de Chile.

MARINI, RUY MAURO (1976): El reformismo y la contrarrevolución, Estudios sobre Chile, México, Ediciones ERA.

MARINI, RUY MAURO (1994): «La crisis del desarrollismo», en Marini, Ruy \& Millán, Márgara (Eds.) La teoría social latinoamericana, México, Ediciones El Caballito.

MEDINA ECHAVARRÍA, JOSÉ (1963): Consideraciones sociológicas sobre el desarrollo económico de América Latina, Mar del Plata, Naciones Unidas. O'DONNELL, GUILLERMO (1972): Modernización y autoritarismo, Buenos Aires, Prometeo.

O'DONNELL, GUILLERMO (1993): «Acerca del Estado, la democratización y algunos problemas conceptuales. Una perspectiva latinoamericana con referencias a países poscomunistas», Desarro/lo Económico, vol. XXXIII, nº 130, pp. 163-184.

ORMAECHEA, EMILIA Y FERNÁNDEZ, VÍCTOR (2017): "Consideraciones sobre el cambio de percepción de Raúl Prebisch en el entendimiento del rol del Estado para el desarrollo latinoamericano (1949-1963)», Papeles del Centro de Investigación, nº 18, pp. 121-144.

PALMA, GABRIEL (1987): La teoría de la dependencia, una revaluación crítica, México, Fondo de Cultura Económica.
PEET, RICHARD (2009): Unholy trinity: the IMF, World Bank, and WTO, Zed Books.

PINTO, ANÍBAL (1965): «Concentración del progreso técnico y de sus frutos en el desarrollo latinoamericano", El Trimestre Económico, vol. XXXII. PINTO, ANÍBAL (1973): Heterogeneidad estructural y modelo de desarrollo reciente de la América Latina, ILPES - CEPAL.

PINTO, ANÍBAL (1980): «La apertura exterior de América Latina», Revista de La CEPAL, n 11, pp. 33-60. PORTANTIERO, JUAN (1989): «La múltiple transformación del Estado latinoamericano», Nueva Sociedad, no 104, pp. 148-158.

PREBISCH, RAÚL ([1949] 1986): «El desarrollo económico de la América Latina y algunos de sus principales problemas», Desarrollo Económico, vol. 26, no 103 pp. 479-502.

PREBISCH, RAÚL (1952): Problemas teóricos y prácticos del crecimiento económico, Santiago de Chile, Naciones Unidas.

PREBISCH, RAÚL (1963): «Hacia una dinámica del desarrollo latinoamericano», CEPAL - Décimo Período de Sesiones.

PREBISCH, RAÚL (1976): «Crítica al capitalismo periférico", Revista de La CEPAL, pp. 7-74.

PREBISCH, RAÚL (1980): "Hacia una teoría de la transformación», Revista de La CEPAL, nº 96, pp. 165-216.

QUIJANO, ANÍBAL (1968): «Dependencia, cambio social y urbanización en Latinoamérica», Revista Mexicana de Sociología, vol. XXX, n 3, pp. 525-570.

ROMERO, LUIS Y ROFMAN, ALEJANDRO (1974): Sistema socioeconómico y estructura regional en la Argentina, Buenos Aires, Amorrortu Editores.

ROSALES, OSVALDO (1988): «Balance y renovación en el paradigma estructuralista del desarrollo latinoamericano", Revista de La CEPAL, no 34 , pp. 19-36. 
SUNKEL, OSVALDO (1967): "Política nacional de desarrollo y dependencia externa», Estudios Internacionales, vol. 1, n 1, pp. 43-75.

SUNKEL, OSVALDO (1970): «Desarrollo, subdesarrollo, dependencia, marginación y desigualdades espaciales; hacia un enfoque totalizante», EURE, vol. 1, no 1 , pp. 13-49.

SUNKEL, OSVALDO (1971): «Capitalismo transnacional y desintegración nacional en América Latina», Estudios Internacionales, vol. 4, n 16, pp. 3-61. SUNKEL, OSVALDO Y ZULETA, GUSTAVO (1990): «Neoes- tructuralismo versus neoliberalismo en los años noventa», Revista de La CEPAL, n 42 , pp. 35-54. SZTULWARK, SEBASTIÁN (2005): El estructuralismo latinoamericano, Buenos Aires, Prometeo - Universidad Nacional de General Sarmiento.

TOYE, JOHN (1987): Dilemmas of Development: Reflections on the Counter-revolution in Development Economics, Oxford, Brasil Blackwell. WOLFE, MARSHALL (1976): «Enfoques del desarrollo: ¿de quién y hacia qué?», Revista de La CEPAL, Primer semestre, pp. 129-172. 